\title{
Highly Selective Skeletal Isomerization of Cyclohexene Over Zeolite-Based Catalysts for High- Purity Methylcyclopentene Production
}

Hua Song ( $\sim$ sonh@ucalgary.ca )

University of Calgary https://orcid.org/0000-0002-2791-1723

Hao Xu

Zhaofei Li

Shijun Meng

Jack Jarvis

University of Calgary

\section{Article}

Keywords: catalytic cyclohexene conversion, skeletal isomerization, selective methylcyclopentene production, zeolite-based catalyst, mechanistic study

Posted Date: December 2nd, 2020

DOl: https://doi.org/10.21203/rs.3.rs-113208/v1

License: (9) (1) This work is licensed under a Creative Commons Attribution 4.0 International License.

Read Full License

Version of Record: A version of this preprint was published at Communications Chemistry on March 11th, 2021. See the published version at https://doi.org/10.1038/s42004-021-00472-8. 


\section{Abstract}

Cyclohexene skeletal isomerization was achieved under mild conditions over rationally designed zeolitebased catalysts with high selectivity towards methylcyclopentene and satisfactory stability for multiple runs. The favorable performance was investigated, which can be attributed to unique acidic, structural and morphologic features of optimized Co/NaUZSM-5 catalyst. Further experimental data suggested that carboncationic mechanism might be followed and the reaction mainly occurs within the internal pores of zeolite structures, which was also validated by DFT study.

\section{Introduction}

Methylcyclopentene ( $\mathrm{mcp}$ ) is a commonly used intermediate in petrochemical industry, which can be produced from cyclohexene through skeletal isomerization reaction.[1, 2] Traditional catalysts for cyclohexene skeletal isomerization are mainly based on metal oxides including silica, alumina, zirconia, titania or their combinations. It is widely observed that the activity of catalyst is positively correlated to increasing amount of acid sites.[1, 3-5] However, highly active catalyst with a large number of acid sites leads to a series of side reactions, lowering the selectivity towards methylcyclopentene. On the other hand, the catalyst with limited amount of acid sites demonstrates insufficient activity for efficient methylcyclopentene production. $[4,6,7]$ A catalyst with both high activity and methylcyclopentene selectivity still remains unreported.

In this work, a series of zeolite-based catalysts were specially designed for triggering cyclohexene conversion under industrially favorable mild conditions of $400^{\circ} \mathrm{C}$ and near atmospheric pressure. A set of commonly used metal oxide-based catalysts were also used as the references for better comparison. A wide variety of characterization tools including micro-GC, GC-MS, TGA, $\mathrm{N}_{2}$ physisorption, $\mathrm{NH}_{3}-\mathrm{TPD}$, ICPOES, SEM and XRD, coupled with DFT calculations were engaged for identifying the propertyperformance relationship of the charged catalysts, based on which an optimization strategy was developed and implemented to guide catalyst rational design and synthesis for achieving maximized selectivity of methylcyclopentene with acceptable cyclohexene conversion.

\section{Experimental}

Details regarding material and catalyst synthesis, reaction process, product analyses, catalyst characterizations, liquid product composition, DFT calculation and thermal equilibrium calculation are shown in the Supplementary Information (SI).

\section{Results And Discussion}

\subsection{Comparison of UZSM-5 and metal oxide catalysts}

First, a novel zeolite-based catalyst with uniform compact cylindrical shape (UZSM-5) was synthesized and compared with various conventional metal oxide-based catalysts. The catalytic performances of 
these catalysts are shown in Fig. 1 and detailed composition of liquid products are listed in Table S8. According to Fig. 1(a), UZSM-5 demonstrates much higher cyclohexene conversion and similar olefin selectivity compared with traditional oxide catalysts, proving its potential for catalytic conversion of cyclohexene to valuable products. However, the selectivity towards aromatics is also the highest. Detailed analysis of generated aromatic products in Fig. 1(b) indicates the type of aromatics varies with different catalysts. UZSM-5 leads to the formation of BTEX (benzene, toluene, ethylbenzene and xylenes) family, and other aromatics including monocyclic species with 9 11 carbon atoms such as mesitylene and limited amount of bicyclic species such as naphthalene are also detected. This can be attributed to the primary function of zeolite-based catalyst for aromatization, which is widely reported and utilized in industry $[8,9]$. Moreover, silica leads to a unique distribution of aromatic products, which mainly consists polycyclic aromatic hydrocarbons with 2 or 3 rings rather than BTEX species. Alumina and titania result in limited production of benzene and toluene, while zirconia demonstrates no aromatic selectivity. The varied aromatic formation characteristic is well understood by the shape selective effect of catalysts with different pore structures, as indicated in Fig. S5. However, despite the dramatic difference in aromatic species, it is indicated in Fig. 1(c) that the main olefin products formed over all catalysts are three isomers of methylcyclopentene, implying that the skeletal isomerization of cyclohexene can be well observed regardless of the charged catalyst structures. To the best of our knowledge, the favorable catalytic performances of cyclohexene isomerization over zeolite-based catalyst have not been reported and are thus worth further investigation.

\subsection{Catalytic performances of zeolite-based catalysts}

In order to get further understanding of catalytic cyclohexene conversion with zeolite-based catalysts, a series of zeolite catalysts were synthesized, and their corresponding performances are compared in Fig. 2. Detailed information of zeolite supports and corresponding naming policy are shown in SI (Materials and catalyst syntheses). According to Fig. 2(a), it is evident that zeolite catalysts show entirely different performances compared to pure thermal pyrolysis process without catalyst in terms of cyclohexene conversion and product selectivity. Detailed analysis of aromatic species in Fig. 2(b) suggests BTEX family is the main product over ZSM- 5 and NaZSM- 5 catalysts, but their formation is greatly inhibited over UZSM-5 series catalysts. Fig. 2(c) witnesses that although no olefin is formed over ZSM-5 and NaZSM- 5 catalysts, methylcyclopentene remains as the main olefin product when UZSM- 5 series catalysts are engaged, implying the unique catalytic performances of UZSM- 5 supported catalyst compared to conventional ZSM- 5 based ones. Comparing UZSM- 5 based catalysts, it can be concluded that ion exchange by $\mathrm{Na}^{+}$and metal loading of cobalt further enhance the selectivity towards methylcyclopentene formation. It is worth noting that over $95 \mathrm{wt} . \%$ methylcyclopentene selectivity is successfully achieved over Co/NaUZSM- 5 catalyst, which is much higher than the value over oxide-based catalysts in Fig. 1. This favorable performance is highly promising for the production of methylcyclopentene with high purity through a simple process, which demonstrates great potential for industrial application with high profitability.

\subsection{Stability test}


In order to evaluate the stability of highly selective cyclohexene skeletal isomerization catalyst, the spent Co/NaUZSM- 5 was collected after the first reaction and directly used in the following runs without further treatment for five consecutive cycles. The results are shown in Fig. 3. It can be clearly seen that the selectivity towards desired product methylcyclopentene remains almost unchanged, strongly indicating the satisfactory stability of the catalyst in multiple runs.

\subsection{Relationship between surface acidity and catalytic performances of zeolite-based catalysts}

From Fig. 2(a), dramatically different performances of zeolite-based catalyst can be witnessed and determination of the reason behind is of great importance. It is well known that the amount of acid sites plays an important role on catalytic performances of zeolite-based catalysts.[10] Therefore, the amount of acid sites in different catalysts was first quantified by $\mathrm{NH}_{3}$-TPD, which is pre-calibrated by standard ZSM-5 zeolite support (Fig. S6 and Table S4). The different surface acidities are further confirmed by insitu pyridine adsorption via DRIFTS analyses (Fig. S7). Then, catalytic performance of zeolite-based catalysts was correlated with the amount of acid sites and the results are shown in Fig. 4. According to Fig. 4(a), the overall catalytic performance of different catalysts demonstrates a clear trend along with increasing amount of acid sites: cyclohexene conversion as well as gas and coke yield go up, and the liquid yield decreases correspondingly. This trend can be explained by the strong capability of cyclohexene adsorption on the acidic sites, which triggers a series of reactions including cracking and coking. The gas composition analysis in Table S1 also indicates hydrocarbon species with 1 4 carbon numbers are formed as the main products of cracking process, which is also consistent with literature report.[8, 11] Besides, the selectivity towards aromatics, olefin and desired product methylcyclopentene also follows a monotonous trend along with increasing amount of acid sites (Fig. 4(b)). The positive correlation between aromatic selectivity and the amount of acid sites suggests that higher acidity is favorable for aromatic formation, which is widely accepted as the main function of zeolite catalysts.[10, 12-15] However, with limited acidity, the aromatic content can be greatly lowered and olefin products with high purity of methylcyclopentene predominates, indicating that aromatization and isomerization are two competing reactions in catalytic cyclohexene conversion process, which can be effectively controlled by tuning the amount of acid sites.

However, since the silica to alumina ratio is maintained at 80:1 in both ZSM-5 and UZSM-5 catalyst, the reason why the amount of acid sites is completely different need to be fully investigated. According to ICP-OES results in Table S5, the diverse acidity of zeolite catalysts can be attributed to the substitution of acid sites by $\mathrm{Na}$ or $\mathrm{K}$, since higher content of $\mathrm{Na}$ and $\mathrm{K}$ leads to lower amount of acid sites. Further calculation indicates the amount of $\mathrm{Na}^{+}$in NaZSM-5 is equivalent to $33 \%$ of theoretical $\mathrm{H}^{+}$amount in ZSM-5, implying the ion exchange process is relatively insufficient. In contrast, UZSM- 5 contains considerable amount of $\mathrm{K}^{+}$, which equals to $75 \%$ of theoretical $\mathrm{H}^{+}$amount. The high potassium content is further proved to be from the template solution TPAOH. Interestingly, further ion exchange of UZSM-5 by $\mathrm{NaOH}$ leads to both high $\mathrm{Na}$ and $\mathrm{K}$ contents, and the total amount is even higher (160\%) than theoretical $\mathrm{H}^{+}$amount, indicating $\mathrm{K}$ is not only present on acid sites but also incorporated into the UZSM-5 
framework structure. In order to further understand the influence of $\mathrm{K}$ incorporation, $\mathrm{N}_{2}$ adsorption/desorption was carried out (Fig. S4 and Table S3). The results indicate that zeolite-based catalysts are all microporous materials and the average pore sizes fall in the range of 0.55 to $0.60 \mathrm{~nm}$, which is highly distinguishable from oxide-based mesoporous materials (Fig. S5). However, the average pore size of UZSM- 5 is larger than that of ZSM-5, accompanied by slightly increased micropore volume and surface area, indicating $\mathrm{K}$ incorporation leads to the enlarged channel structure of zeolites. The expansion of framework structure is further evidenced by XRD patterns as shown in Fig. S8, since the peaks of (011) and (200) crystalline planes shift evidently to the lower end. Moreover, the relative intensities of diffraction peaks with lower indices is also higher in UZSM-5 than those in ZSM-5, suggesting the presence of more fine zeolite crystals. This conclusion is also confirmed by SEM images in Fig. S9, since more uniformly shaped fine particles are observed in UZSM-5 compared to ZSM-5. Based on these observations, the unique catalytic performances of UZSM- 5 can be better explained by the change of surface and structural features, where the incorporation of K plays a major role. On one hand, $\mathrm{K}$ lowers the amount of acid sites through direct $\mathrm{H}^{+}$substitution, which is already well documented.[16] On the other hand, the presence of $\mathrm{K}$ in the zeolite framework structure also leads to enlarged micropores and uniform morphology of zeolite catalysts, which is also reported in previous studies.[17, 18] Then, more efficient ion exchange process can be realized and the acidity can be more effectively controlled, which is proved by high $\mathrm{Na}$ content in NaUZSM- 5 and corresponding low acidity. The changes of acidity, structure and morphology make combined contributions to the favorable methylcyclopentene selectivity.

\subsection{Mechanism interpretation}

In previous studies, cyclohexene skeletal isomerization is reported to proceed through a carboncationic (carbenium) mechanism as shown in Scheme 1.[1] First, cyclohexene can be selectively adsorbed through the $\mathrm{C}=\mathrm{C}$ double bond on the catalytic surface, particularly on the Bronsted acid sites. Then, the Bronsted acid sites act as the proton donor and the cyclohexene get protonated to form a carboncationic intermediate (A). Next, the carboncationic intermediate of cyclohexene $(\mathbf{A})$ undergoes an isomerization process to produce another carboncationic intermediate of methyl cyclopentene (B). B is further stabilized to form a tertiary carbenium (C) or a secondary carbenium (D). C finally forms 1 methylcyclopentene through dehydrogenation and $\mathbf{D}$ forms 3-methylcyclopentene. Besides, a further charge transfer of $\mathbf{D}$ forms another secondary carbenium $\mathbf{E}$ and 4-methylcyclopentene can be generated subsequently. Besides, A and B could also form byproducts cyclohexane (cha) and methylcyclopentane (mcpa) through hydrogen transfer, respectively, which are also detectable with limited selectivity in the experiments (Table S8). In general, tertiary carbenium is more stable than secondary carbenium because the positive charge can be better dispersed through three groups linked to the carboncationic center. Therefore, 1-methylcyclopentene should be the main product. Comparing two secondary carbeniums (D and E), E can only be formed through an extra charge transfer process, and thus the formation probability of 4-methylcyclopentene should be lower than that of 3-methylcyclopentene. In summary, the relative content of three different isomers should follow the sequence of 1-methylcyclopentene $>3$ methylcyclopentene $>$ 4-methylcyclopentene. 
In order to confirm the proposed mechanism, relative content of three methylcyclopentene isomers collected from all runs are compared in Fig. 5. As expected, the relative content follows the same sequence in all entries (within 10\% relative error): 1-methylcyclopentene > 3- methylcyclopentene $>4$ methylcyclopentene, thus supporting the proposed carboncationic mechanism. This sequence is also consistent with previous literature report [2]. Besides, a further thermodynamic equilibrium calculation also coincides well with experimental results (Table S10), further confirming the reliability of the conclusion. It is suggested that despite of the intrinsic differences of charged catalytic materials, the cyclohexene skeletal isomerization process can take place by following a similar mechanism.

\subsection{Effect of Co addition}

Based on aforementioned mechanism and characterization results, the effects of Co introduction can also be interpreted. $\mathrm{NH}_{3}$-TPD results in Table $\mathrm{S} 4$ indicate that the presence of Co leads to the transition of weak acid sites to strong acid sites, which can also be clearly seen by the emergence of new peak at 370 ${ }^{\circ} \mathrm{C}$ in Fig. S6. Moreover, the peaks of Lewis acid sites are also intensified in DRIFTS analyses, as shown in Fig. S7. These observations suggest that Co interacts with NaUZSM- 5 catalyst to generate more strong Lewis acid sites, facilitating the adsorption of cyclohexene. This effect results in slightly higher cyclohexene conversion, and the methylcyclopentene selectivity can also be improved because of wellcontrolled Bronsted acidity.

In order to get more clues of the Co effect, a series of NaUZSM- 5 catalysts with difference Co contents were prepared and evaluated and the results are shown in Fig. 6. According to Fig. 6(a), cyclohexene conversion increases gradually along with increasing Co contents, which can be due to stronger cyclohexene adsorption. As expected, better olefin selectivity can also be observed when Co content increases from 0 to $10 \mathrm{wt} \%$. However, lowered olefin selectivity is observed when Co content reaches 15 wt\%, which might be due to the blocking of pore structures caused by excessive Co loading. This hypothesis is further supported by $\mathrm{N}_{2}$ adsorption/desorption analysis of Co/NaUZSM- 5 catalysts with different Co loadings (Table S6): the micropore surface area and pore volume declines significantly along with increasing Co content. The consistency between experimental results and anticipations further confirm the conclusions regarding the interaction between Co and zeolite catalyst.

\subsection{Location preference: external surface vs. internal pores of zeolite structure}

To further investigate the location preference of cyclohexene skeletal isomerization over zeolite-based catalyst, Co/NaUZSM- 5 catalyst was treated with an innovative inner pore blocking technique and the produced catalyst was labelled as Co/NaUZSM-5-IPB. According to Table S7, the micropore surface area of Co/NaUZSM-5-IPB is lower than Co/NaUZSM-5, while the external surface area remains almost unchanged, indicating the inner pore structure of Co/NaUZSM- 5 is successfully and exclusively blocked to a certain degree. Then, the catalytic performance of two catalysts are compared in Fig. 7. From Fig. $7(a)$, an apparent decrease of cyclohexene conversion from $47 \%$ to $25 \%$ is observed, accompanied with the lowered olefin selectivity. Detailed analysis of olefin species in Fig. 7(b) also demonstrates that the 
selectivity towards methylcyclopentene, particularly 1-methylcyclopentene, is also declined. Since the external surface area of two catalysts are similar, the deteriorated catalytic performance of Co/NaUZSM5-IPB could only be attributed to the partially blocked inner pore structure. Therefore, the cyclohexene skeletal reaction is experimentally proved to preferably proceed in the inner pores of zeolite-based catalysts.

In order to strengthen this conclusion, corresponding DFT calculation was also carried out. The optimized structures of cyclohexene adsorption on the external surface and within the internal pore of zeolite-based catalyst are shown in Fig. 8. According to the calculation results, the adsorption of cyclohexene in the internal pore of zeolite-based catalyst is $20 \mathrm{~kJ} \mathrm{~mol}^{-1}$ lower than that on the external surface, strongly supporting the reaction prefers to take place in the internal pores rather than on the external surface of the catalyst structure.

\subsection{Different surface acidity dependence: zeolite-based catalyst vs. metal oxide-based catalysts}

As mentioned before, a negative correlation between methylcyclopentene selectivity and the amount of acid sites in zeolite-based catalysts is observed, which is completely contrary to that over conventional metal oxide-based catalysts. Based on the discussion above, a more in-depth explanation can be proposed regarding the different dependence on the amount of acid sites over these two types of catalysts. According to $\mathrm{N}_{2}$ adsorption/desorption analysis, the pore size of zeolite-based catalysts is proved to be within the range of $0.55-0.6 \mathrm{~nm}$, which matches well with the kinetic diameter of cyclohexene.[19] Therefore, the cyclohexene molecules diffused within the inner pore will have strong space restriction and get full contact with the internal wall of the zeolite structure. Under this circumstances, if there are abundant acidic sites, it is highly possible that cyclohexene will interact with more than one acidic site, resulting in uncontrollable over-protonation and the well-recognized aromatization pathway for benzene formation.[8] Therefore, only limited and sparsely distributed acidic sites on the surface of zeolite-based catalysts will favor isomerization process. On the other side, metaloxide based catalysts engaged in this study are all mesoporous materials with much larger pore size. Therefore, there is almost no space restriction for cyclohexene adsorption, resulting in single-site adsorption regardless of the amount of acid sites. Then, the presence of more acidic sites leads to the adsorption of more cyclohexene molecules and higher isomerization activity can thus be expected. In summary, the opposite dependence on the amount of acid sites over zeolite-based and metal oxide-based catalyst might be mainly due to the different space restriction of cyclohexene adsorption caused by pore size distribution of the charged catalytic material, implying that the reaction might be highly shape selective.

\section{Conclusions}

In conclusion, highly selective skeletal isomerization of cyclohexene to produce methylcyclopentene with high purity is realized using Co/NaUZSM- 5 catalyst. K plays an important role during the synthesis of UZSM-5, which noticeably changes the amount of acid site, pore structure as well as morphology of 
zeolite catalyst. Co can interact with UZSM- 5 by modifying the type and strength of acid sites, which finely tunes the catalytic performances. Unprecedent $96.8 \mathrm{wt} . \%$ high liquid yield and $95.8 \mathrm{wt} . \%$ methylcyclopentene selectivity can be achieved with satisfactory stability. A similar carboncationic mechanism of skeletal isomerization is observed over all catalysts under current investigation, leading to a consistent distribution of three methylcyclopentene isomers. The skeletal isomerization reaction is proved to take place more preferably in the inner pores rather than on the external surface of zeolite structure through employing an innovative selective inner pore blocking strategy. DFT study was further performed and the simulation results are in great agreement with experimental observations. Finally, the reverse dependence on the amount of acid sites over zeolite-based and metal oxide-based catalyst suggests the pore structure of catalytic material is also essential for catalytic performances due to space restriction effects. This work provides extra insight into catalytic cyclohexene pyrolysis process in terms of selective formation of desired high-value products. The knowledge gained from this study thus provides a methodology of preparing catalysts with maximized isomerization and limited aromatization selectivity, which can also be used as a platform material for other reaction systems where isomerization is preferred.

\section{Declarations}

\section{Acknowledgments}

The authors gratefully acknowledge the financial supports from Kara Technologies Inc., Natural Sciences and Engineering Research Council of Canada (NSERC) through collaborative research and development program (CRDPJ/531607-18) and Alberta Innovates (Al 2552).

\section{Author contributions}

H. X. contributed catalyst preparation, reaction evaluation, data analysis and paper writing. Z. L. contributed sample measurement and paper revision. S. M. contributed DFT calculation and thermodynamic calculation. J. J. contributed catalyst synthesis and characterization. H. S. contributed experimental design, paper structuring and final confirmation.

\section{Competing interests}

The authors declare no competing interests.

\section{References}

[1] Campelo JM, Garcia A, Gutierrez JM, Luna D, Marina JM. Skeletal isomerization of cyclohexene on Al203 and AlP04-Al203 catalysts. Canadian Journal of Chemistry 1984;62:1455-8.

[2] Campelo JM, Garcia A, Luna D, Marinas JM. TEXTURAL PROPERTIES, SURFACE CHEMISTRY AND CATALYTIC ACTIVITY IN CYCLOHEXENE SKELETAL ISOMERIZATION OF ACID TREATED NATURAL 
SEPIOLITES. Materials Chemistry and Physics 1989;24:51-70.

[3] Rozwadowski M, Datka J, Lezanska M, Wloch J, Erdmann K, Kornatowski J. Al-MCM-41: its acidity and activity in cyclohexene conversion. Physical Chemistry Chemical Physics 2001;3(22):5082-6.

[4] Navio JA, Colon G, Macias M, Campelo JM, Romero AA, Marinas JM. Catalytic Properties of ZrO2SiO2: Effects of Sulfation in the Cyclohexene Isomerization Reaction. Journal of Catalysis 1996;161:60513.

[5] Campelo JM, Garcia A, Luna D, Marinas JM, Moreno MS. AlPO4-TiO2 catalysts. Part 2.-Structure, texture and catalytic activity of systems precipitated with ammonia or ethene oxide. J Chem Soc, Faraday Trans 1989;85(8):2535-53.

[6] Lanver A, Ebel K, Klopsch R, Bertleff W, Teles JH, Kronemayer H, et al. Method for the production of 1methylcyclopentane derivatives. In: Organization WIP, ed. C07C 5/29 ed.; 2012.

[7] Navio JA, Colon G, Macias M, Campelo JM, Romero AA, Marinas JM. Catalytic properties of sulfated and non-sulfated $\mathrm{ZrO} 2-\mathrm{SiO} 2$ : effects of the sulfation submitted before or after the calcination process, in the cyclohexene isomerization reaction. Journal of Molecular Catalysis A: Chemical 1998;135:155-62.

[8] Urdă A, Tel'biz G, Săndulescua I. Reaction pathways for the aromatization of cyclohexane and cyclohexene on Zn/H-ZSM-5 zeolites. Studies in Surface Science and Catalysis 2001;135:278-85.

[9] Borade RB, Zhang B, Clearfield A. Selective dehydrogenation ofcyclohexene to benzene using Pdexchanged alpha-zirconium phosphate. Catalysis Letters 1997;45:233-5.

[10] Jarvis J, Wong A, He P, Li Q, Song H. Catalytic aromatization of naphtha under methane environment: Effect of surface acidity and metal modification of HZSM-5. Fuel 2018;223:211-21.

[11] Wang J, Sun W, Wang G, Fan X, Lee Y-Y, Law CK, et al. Understanding benzene formation pathways in pyrolysis of two C6H10 isomers: Cyclohexene and 1,5-hexadiene. Proceedings of the Combustion Institute 2019;37(1):1091-8.

[12] Austin D, Wang A, Harrhy JH, Mao X, Zeng H, Song H. Catalytic aromatization of acetone as a model compound for biomass-derived oil under a methane environment. Catalysis Science \& Technology 2018;8(19):5104-14.

[13] He P, Jarvis J, Meng S, Wang A, Kou S, Gatip R, et al. Co-aromatization of methane with olefins: The role of inner pore and external surface catalytic sites. Applied Catalysis B: Environmental 2018;234:23446.

[14] Li Q, He P, Jarvis J, Bhattacharya A, Mao X, Wang A, et al. Catalytic co-aromatization of methane and heptane as an alkane model compound over Zn-Ga/ZSM-5: A mechanistic study. Applied Catalysis B: Environmental 2018;236:13-24. 
[15] Li Q, Zhang F, Jarvis J, He P, Yung MM, Wang A, et al. Investigation on the light alkanes aromatization over Zn and Ga modified HZSM-5 catalysts in the presence of methane. Fuel 2018;219:331-9.

[16] Yan B, Tao L-Z, Mahmood A, Liang Y, Xu B-Q. Potassium-Ion-Exchanged Zeolites for Sustainable Production of Acrylic Acid by Gas-Phase Dehydration of Lactic Acid. ACS Catalysis 2016;7(1):538-50.

[17] Jarvis JS, Harrhy JH, Wang A, Bere T, Morgan DJ, Carter JH, et al. Inhibiting the Dealkylation of Basic Arenes during n-Alkane Direct Aromatization Reactions and Understanding the C6 Ring Closure Mechanism. ACS Catalysis 2020;10(15):8428-43.

[18] Liu C, Gu W, Kong D, Guo H. The significant effects of the alkali-metal cations on ZSM-5 zeolite synthesis: From mechanism to morphology. Microporous and Mesoporous Materials 2014;183:30-6.

[19] Weng Y, Qiu S, Ma L, Liu Q, Ding M, Zhang Q, et al. Jet-Fuel Range Hydrocarbons from BiomassDerived Sorbitol over Ni-HZSM-5/SBA-15 Catalyst. Catalysts 2015;5(4):2147-60.

\section{Figures}



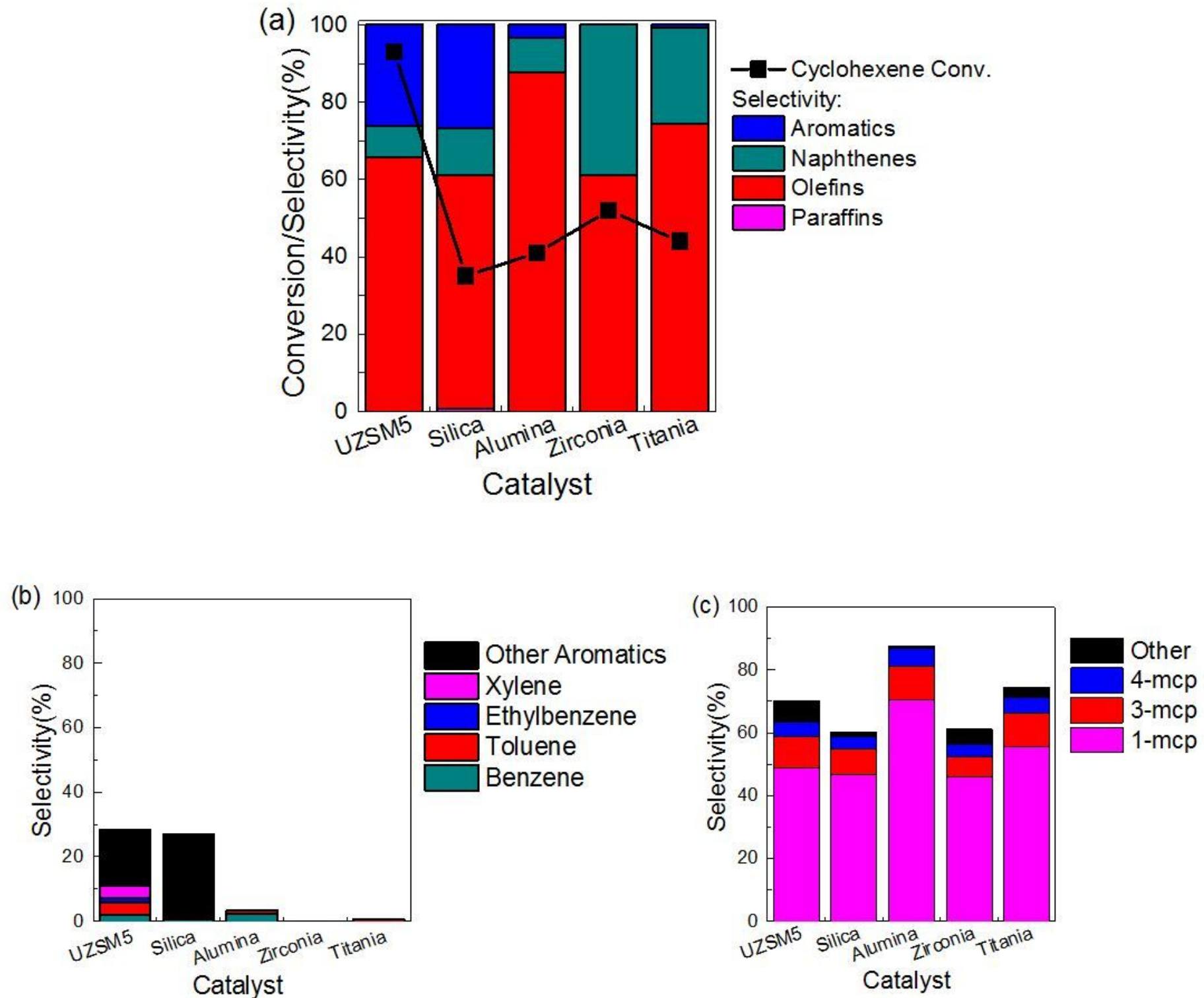

Figure 1

Performances of UZSM-5 and metal oxides for catalytic cyclohexene pyrolysis. (a) Cyclohexene conversion and PONA selectivity, (b) Selectivity of aromatic species, (c) Selectivity of olefin species. 

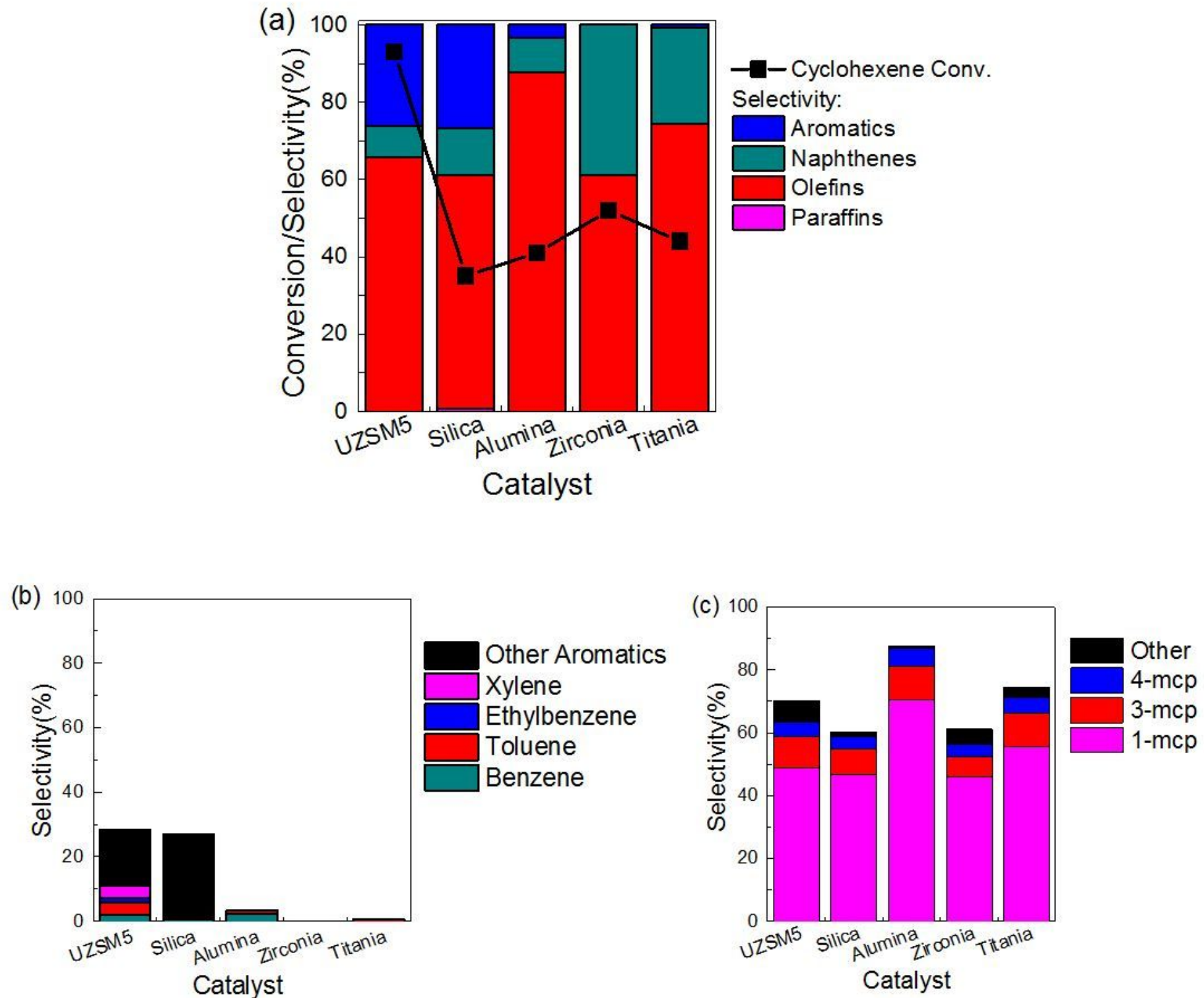

Figure 1

Performances of UZSM-5 and metal oxides for catalytic cyclohexene pyrolysis. (a) Cyclohexene conversion and PONA selectivity, (b) Selectivity of aromatic species, (c) Selectivity of olefin species. 

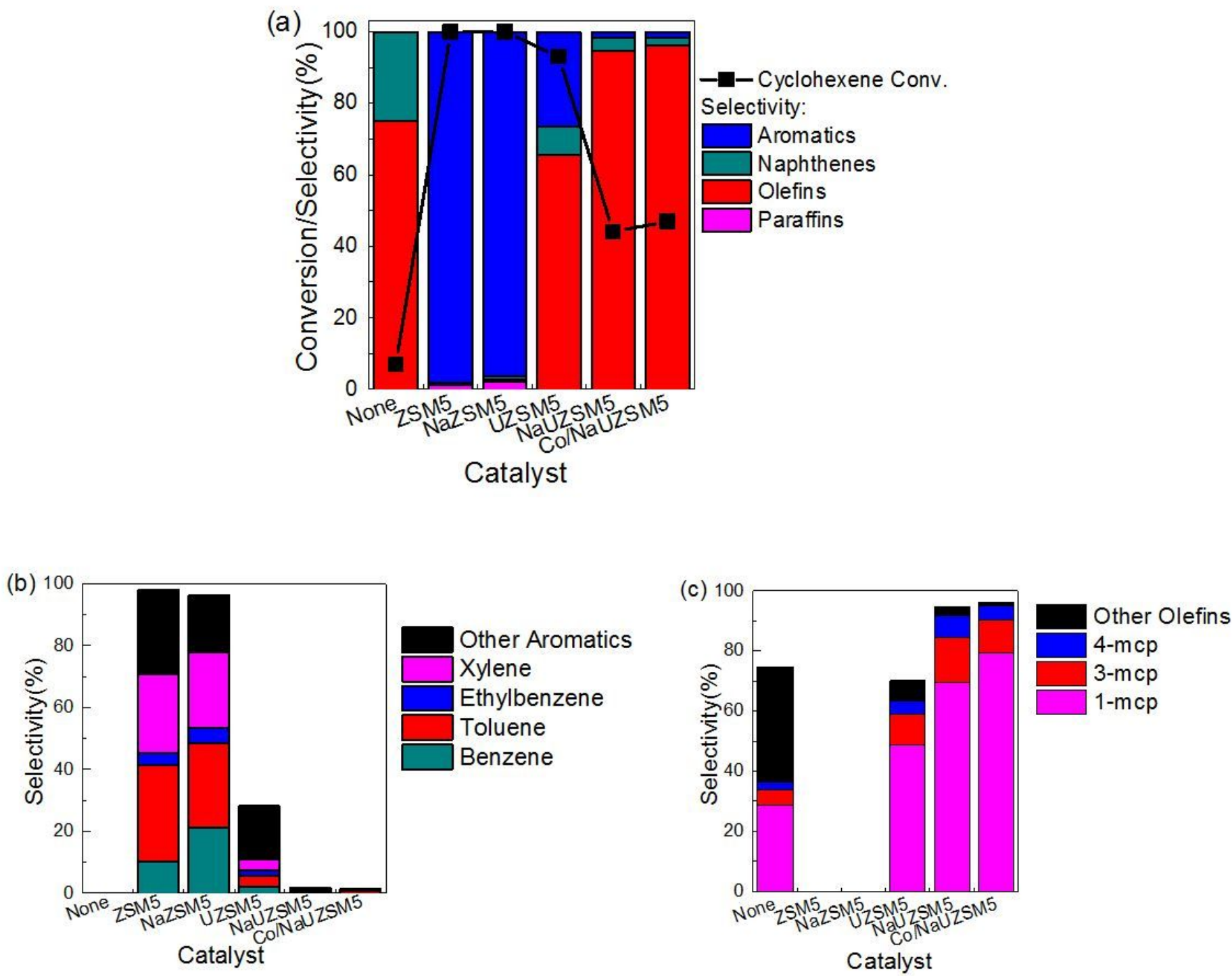

Figure 2

Performances of zeolite-based catalysts for cyclohexene pyrolysis. (a) Cyclohexene conversion and PONA selectivity, (b) Selectivity of aromatic species, (c) Selectivity of olefin species. 

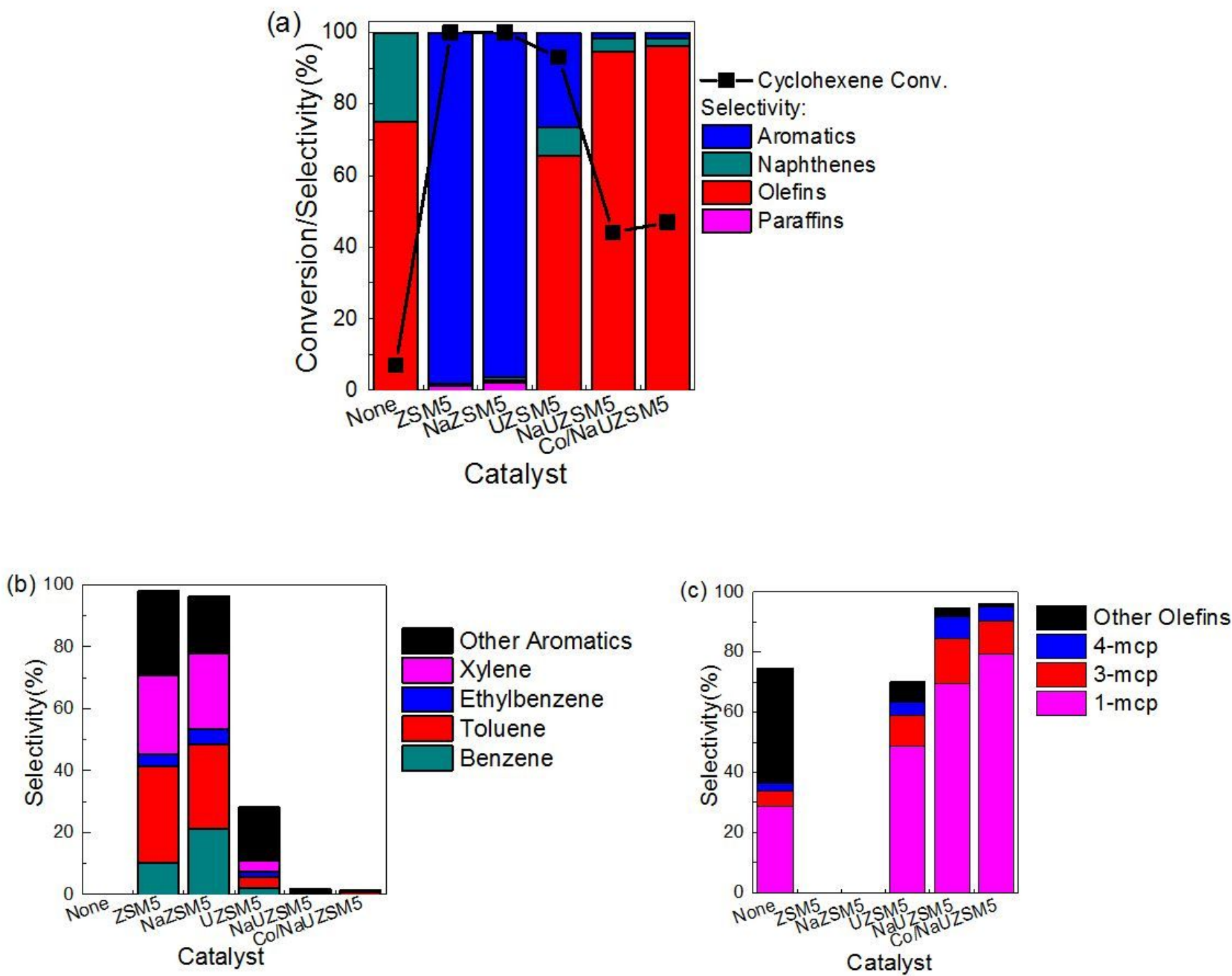

Figure 2

Performances of zeolite-based catalysts for cyclohexene pyrolysis. (a) Cyclohexene conversion and PONA selectivity, (b) Selectivity of aromatic species, (c) Selectivity of olefin species. 


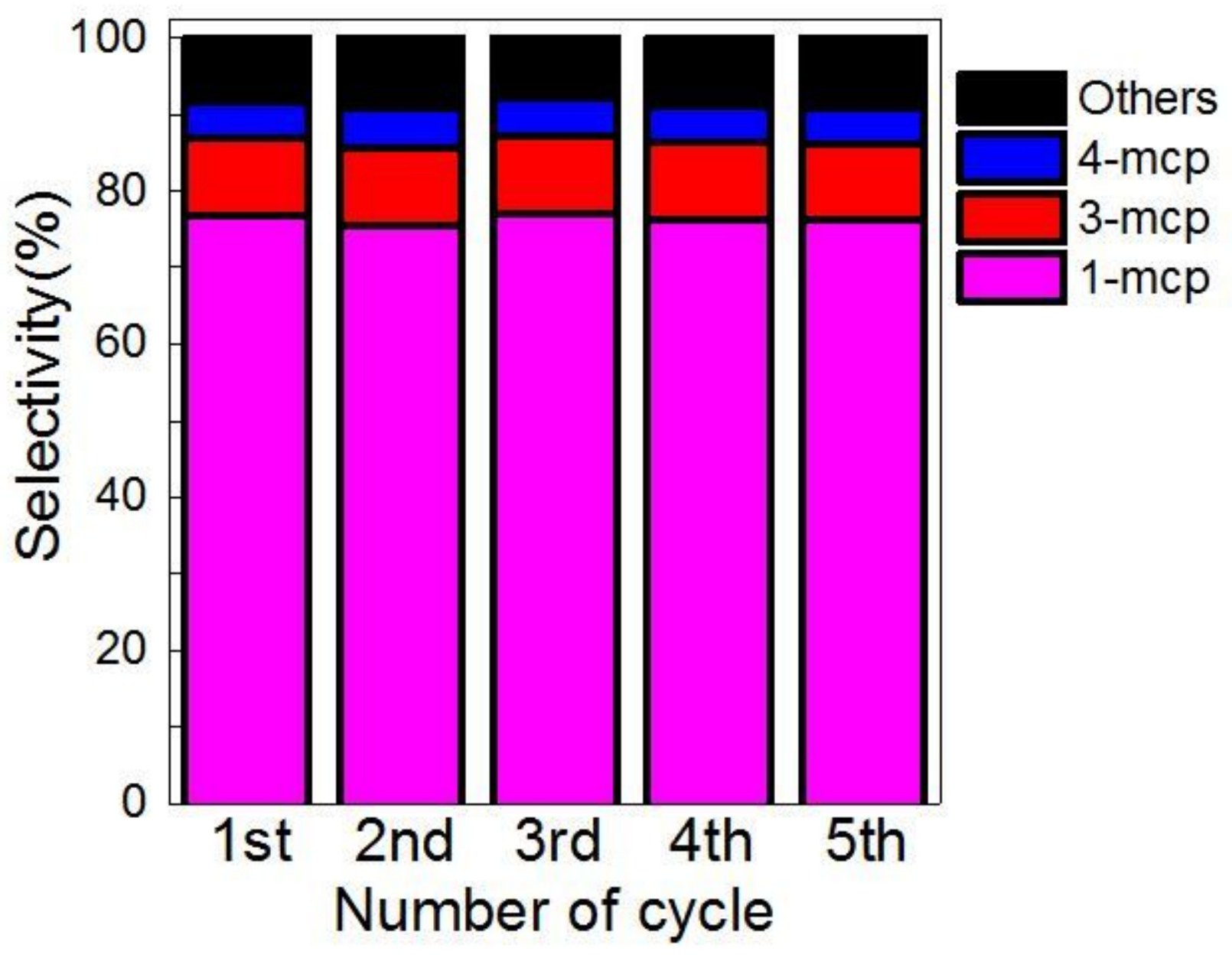

Figure 3

Catalytic performance of $\mathrm{Co} / \mathrm{NaUZSM}-5$ in five reaction cycles. 


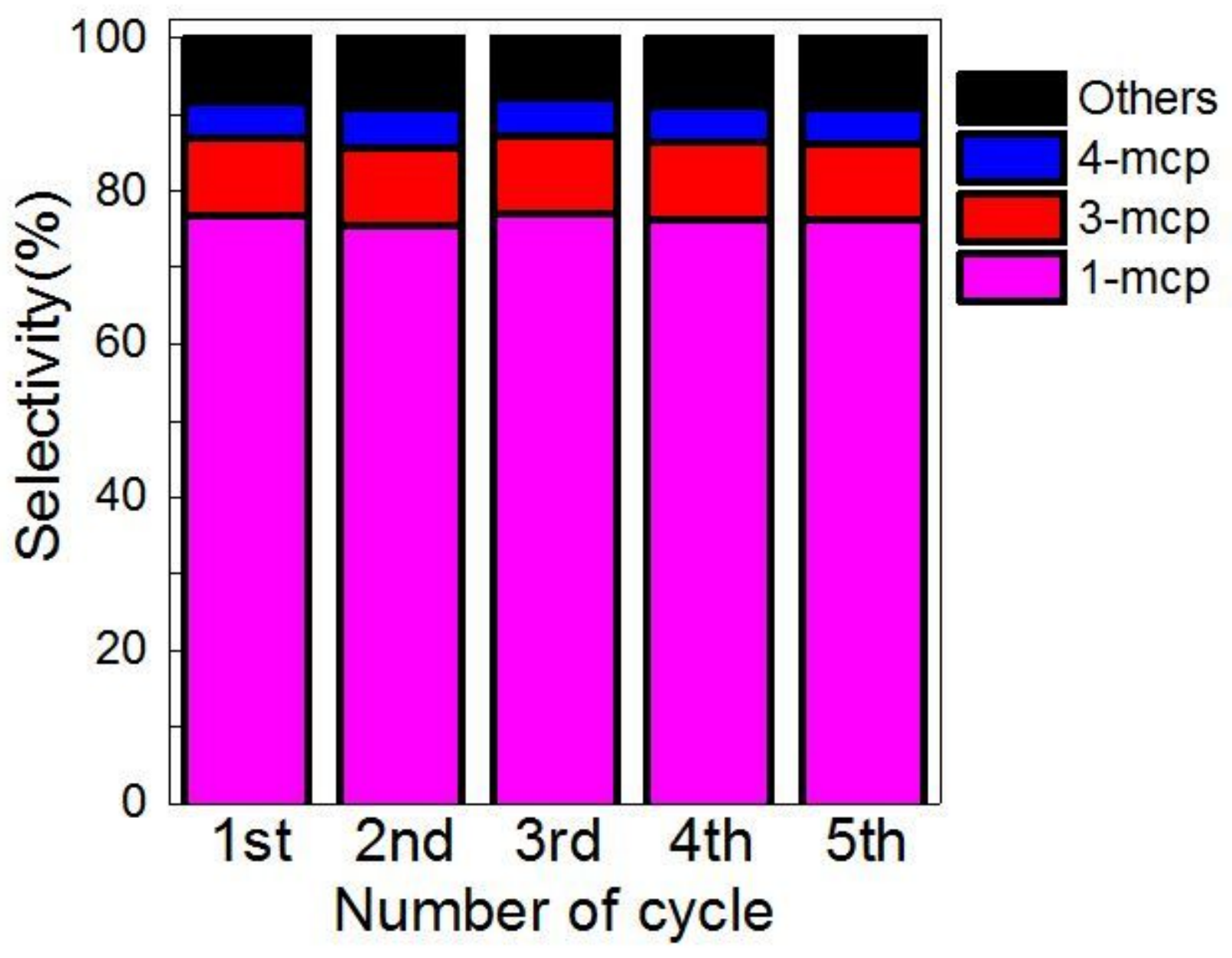

Figure 3

Catalytic performance of $\mathrm{Co} / \mathrm{NaUZSM}-5$ in five reaction cycles.
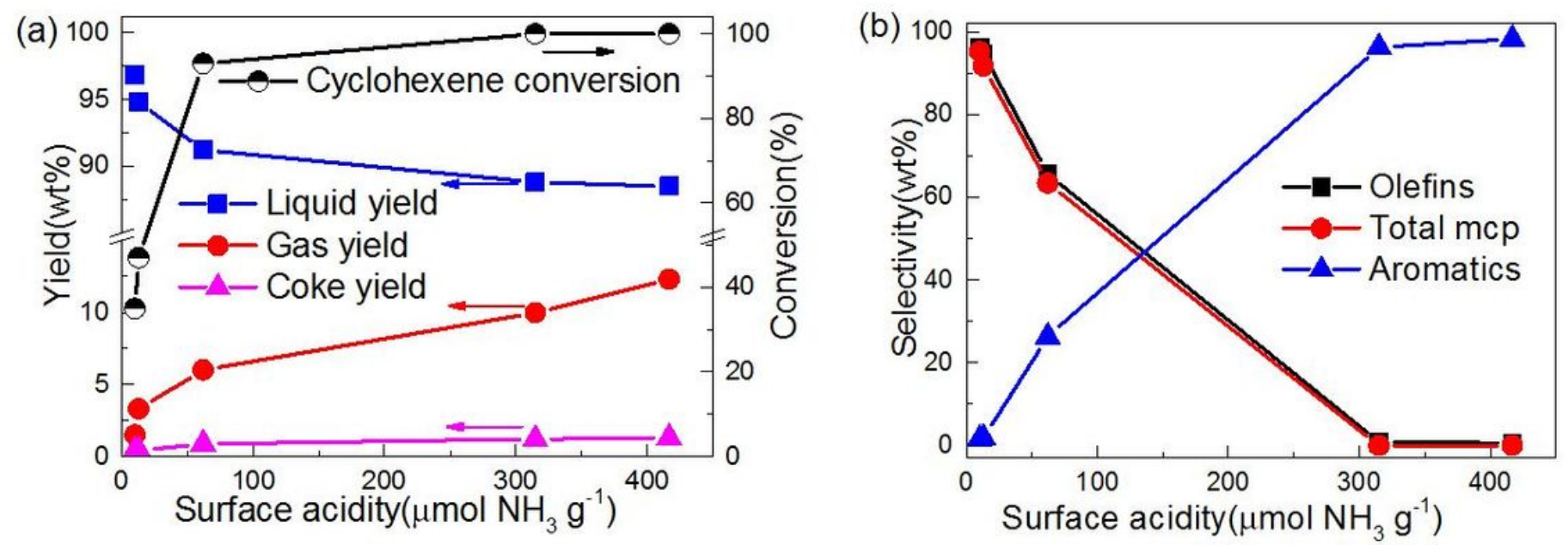

Figure 4 
Relationship between catalytic performance and the surface acidity of catalysts. (a) Overall analysis, (b) Selectivity of olefin, methylcyclopentene and aromatics.
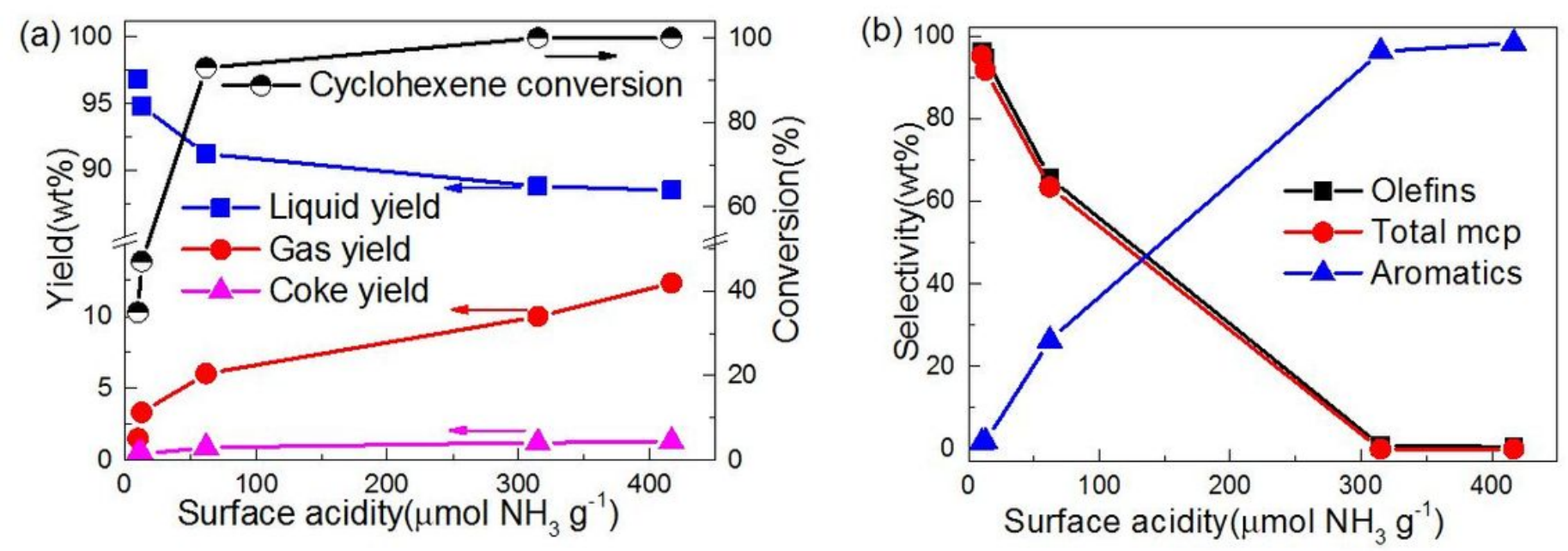

\section{Figure 4}

Relationship between catalytic performance and the surface acidity of catalysts. (a) Overall analysis, (b) Selectivity of olefin, methylcyclopentene and aromatics.

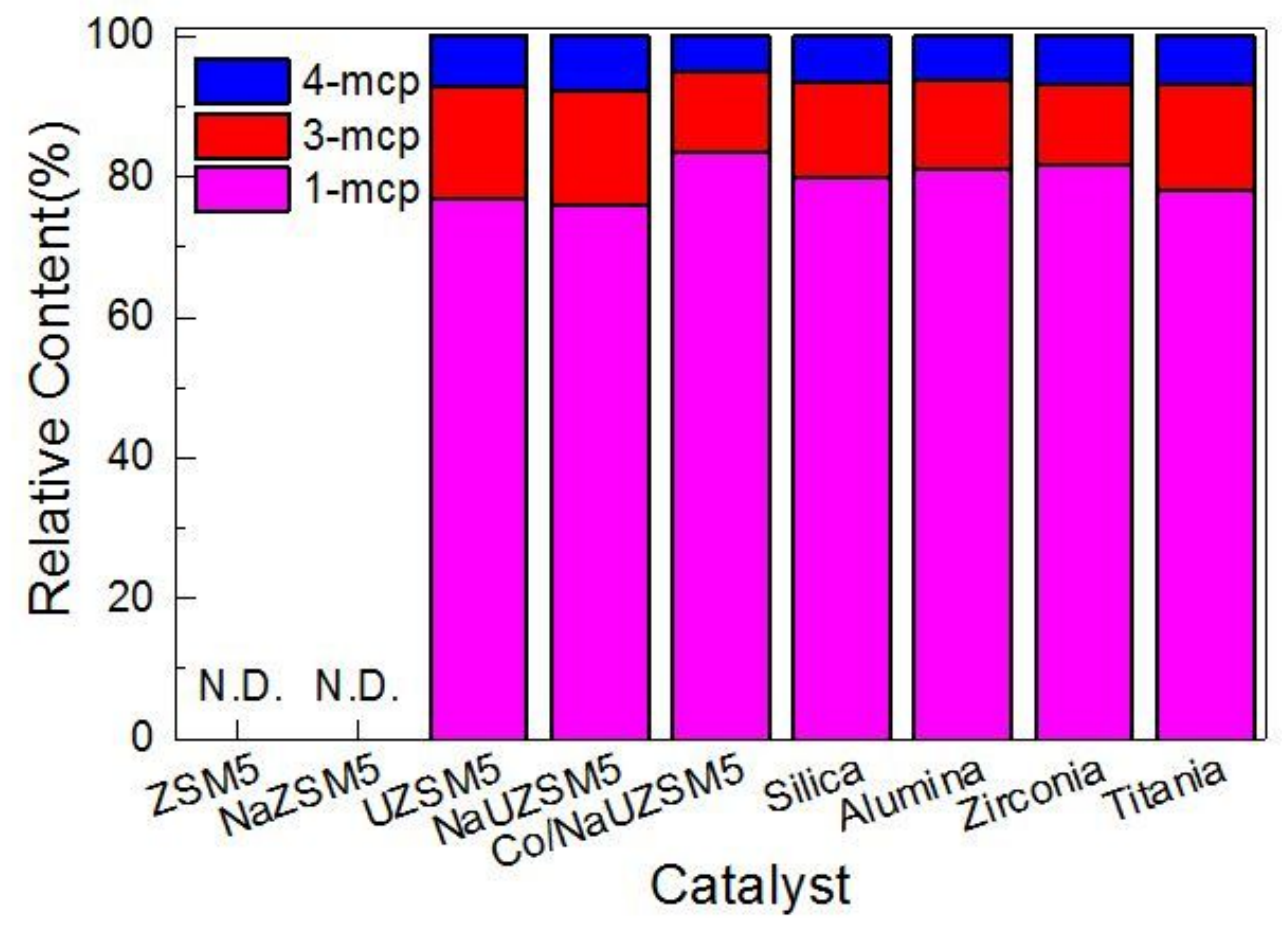

Figure 5 
Relative content of three isomers of methylcyclopentene formed over various catalysts. N.D. represents no methylcyclopentene product is detected.

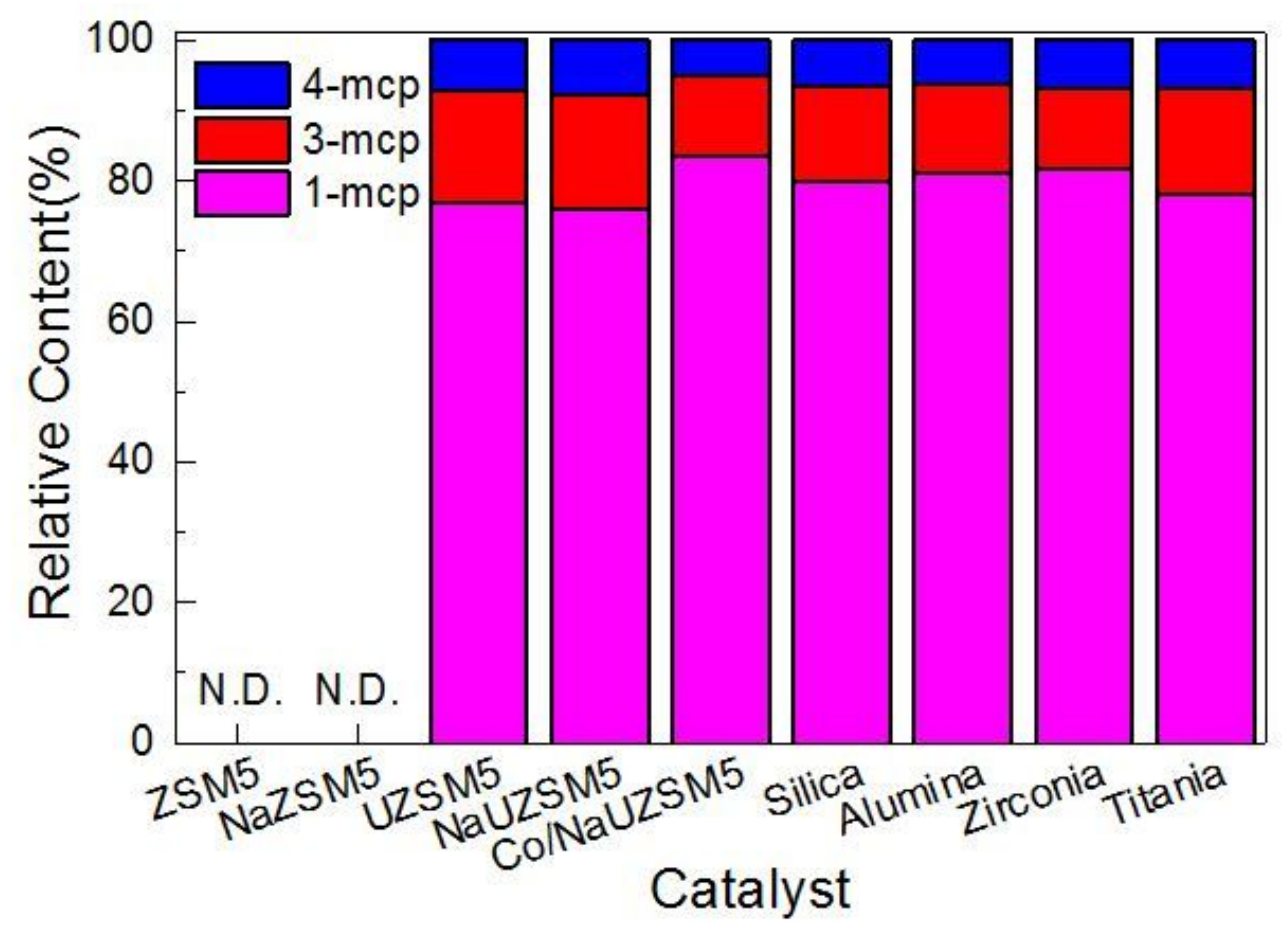

Figure 5

Relative content of three isomers of methylcyclopentene formed over various catalysts. N.D. represents no methylcyclopentene product is detected. 

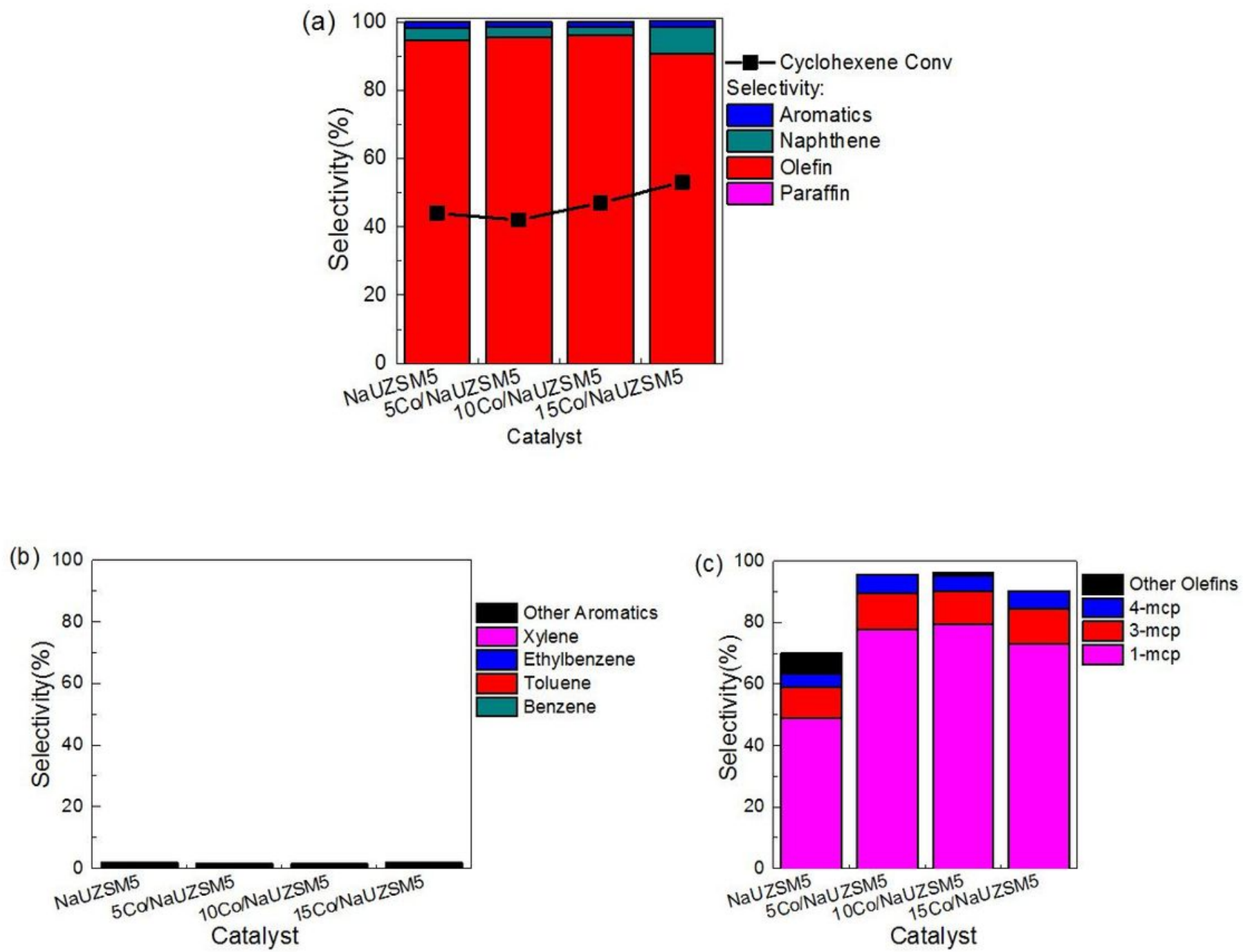

Figure 6

Performances of NaUZSM-5 with different Co loading for catalytic cyclohexene pyrolysis. (a)

Cyclohexene conversion and PONA selectivity, (b) Selectivity of aromatic species, (c) Selectivity of olefin species. 

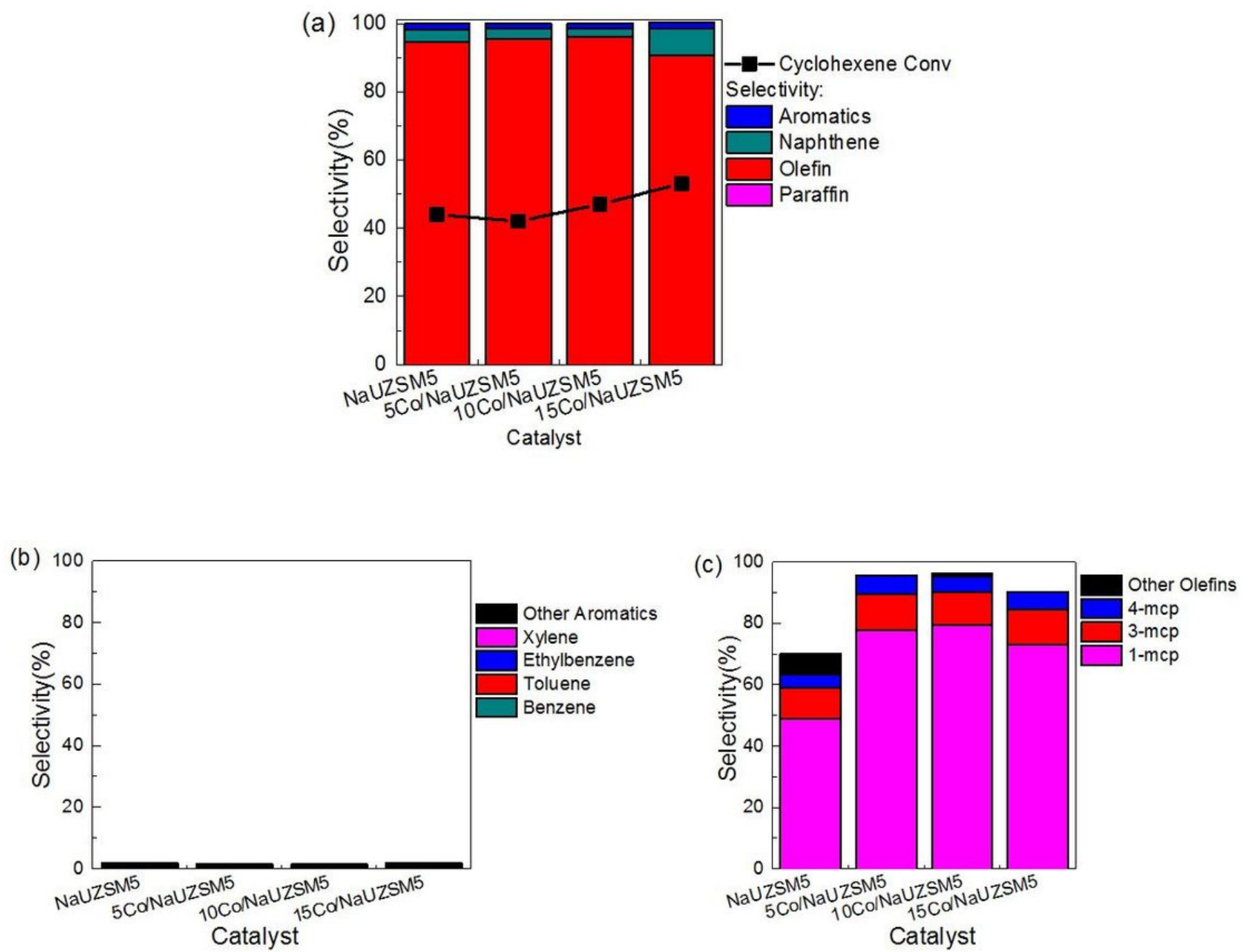

Figure 6

Performances of NaUZSM-5 with different Co loading for catalytic cyclohexene pyrolysis. (a) Cyclohexene conversion and PONA selectivity, (b) Selectivity of aromatic species, (c) Selectivity of olefin species. 
(a)

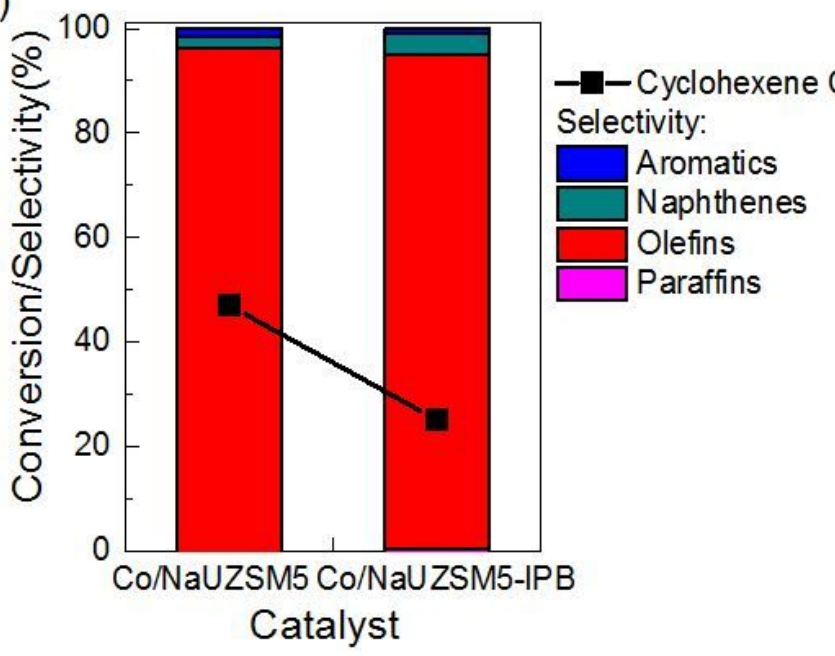

(b) 100

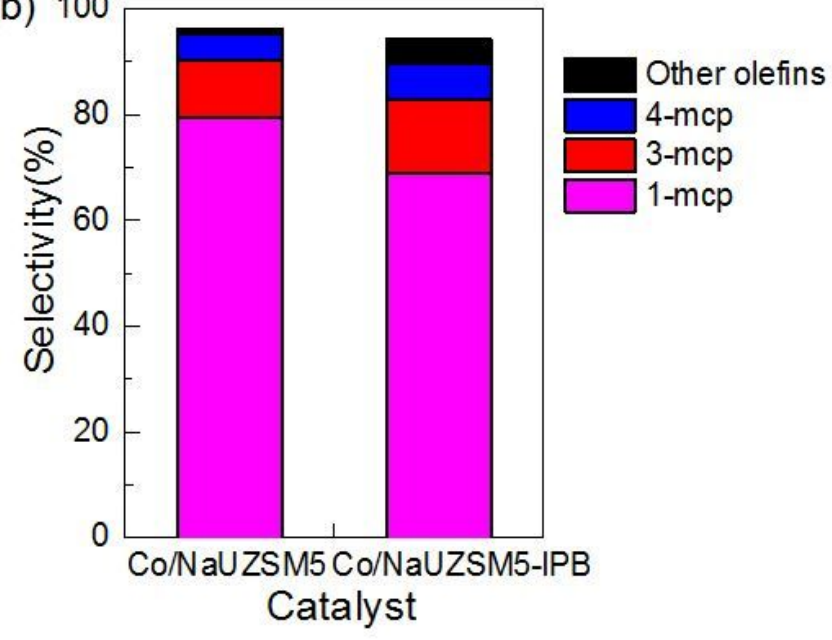

Figure 7

Performances of Co/NaUZSM5 and Co/NaUZSM5-IPB for cyclohexene pyrolysis. (a) Cyclohexene conversion and PONA selectivity, (b) Selectivity of olefin species.

(a)

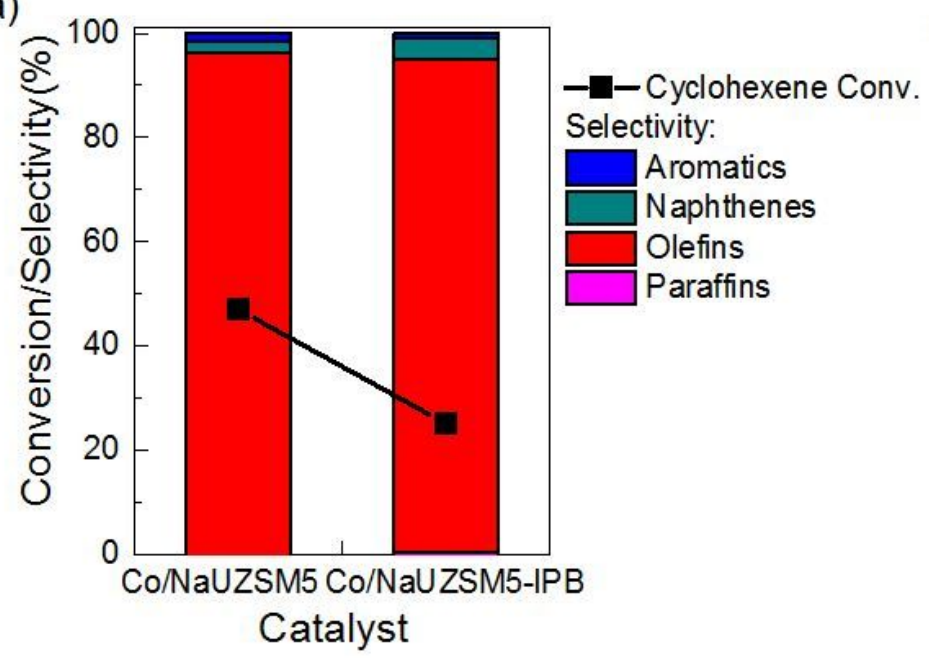

(b) 100

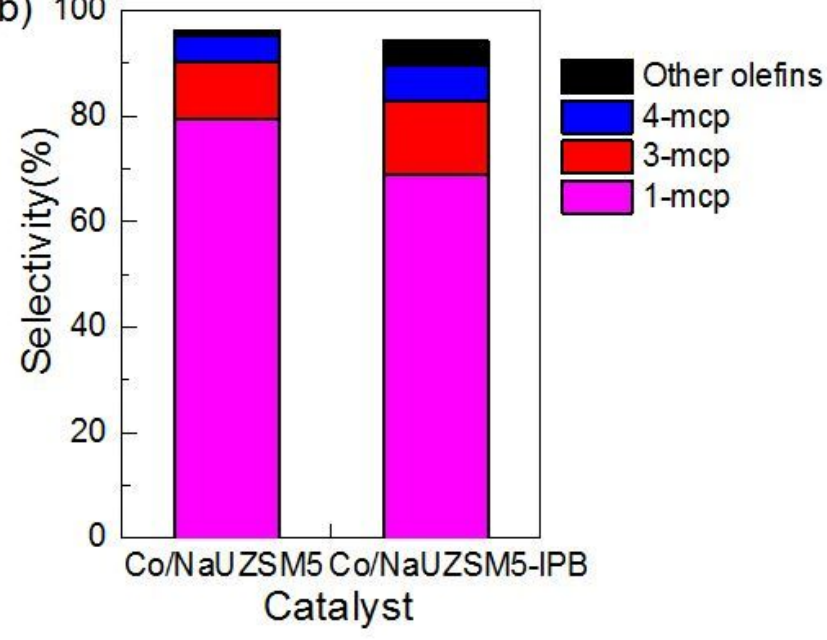

Figure 7

Performances of Co/NaUZSM5 and Co/NaUZSM5-IPB for cyclohexene pyrolysis. (a) Cyclohexene conversion and PONA selectivity, (b) Selectivity of olefin species. 

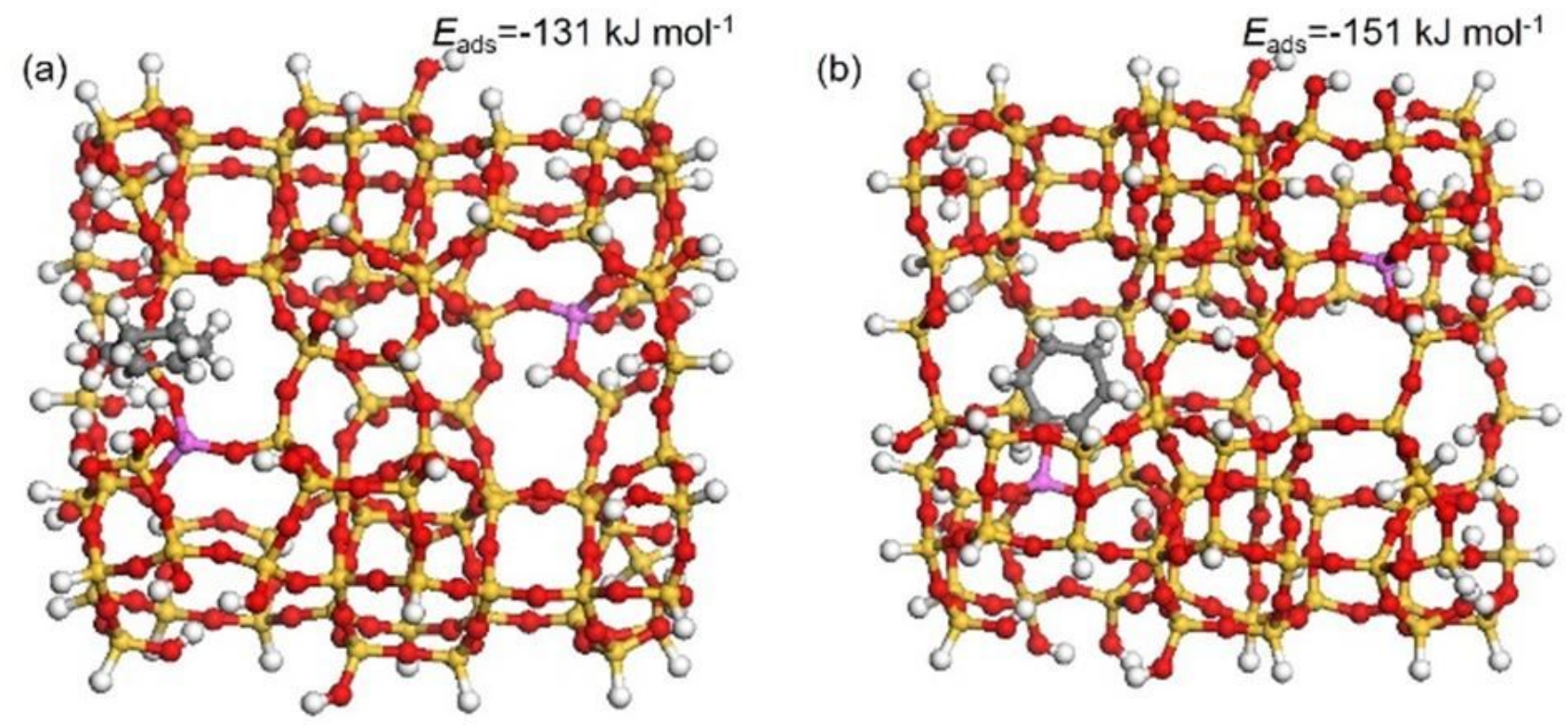

Figure 8

Optimized structure of adsorbed cyclohexene (a) on the external surface, (b) within the internal pore of zeolite-based catalyst. The corresponding adsorption energies Eads are also given.
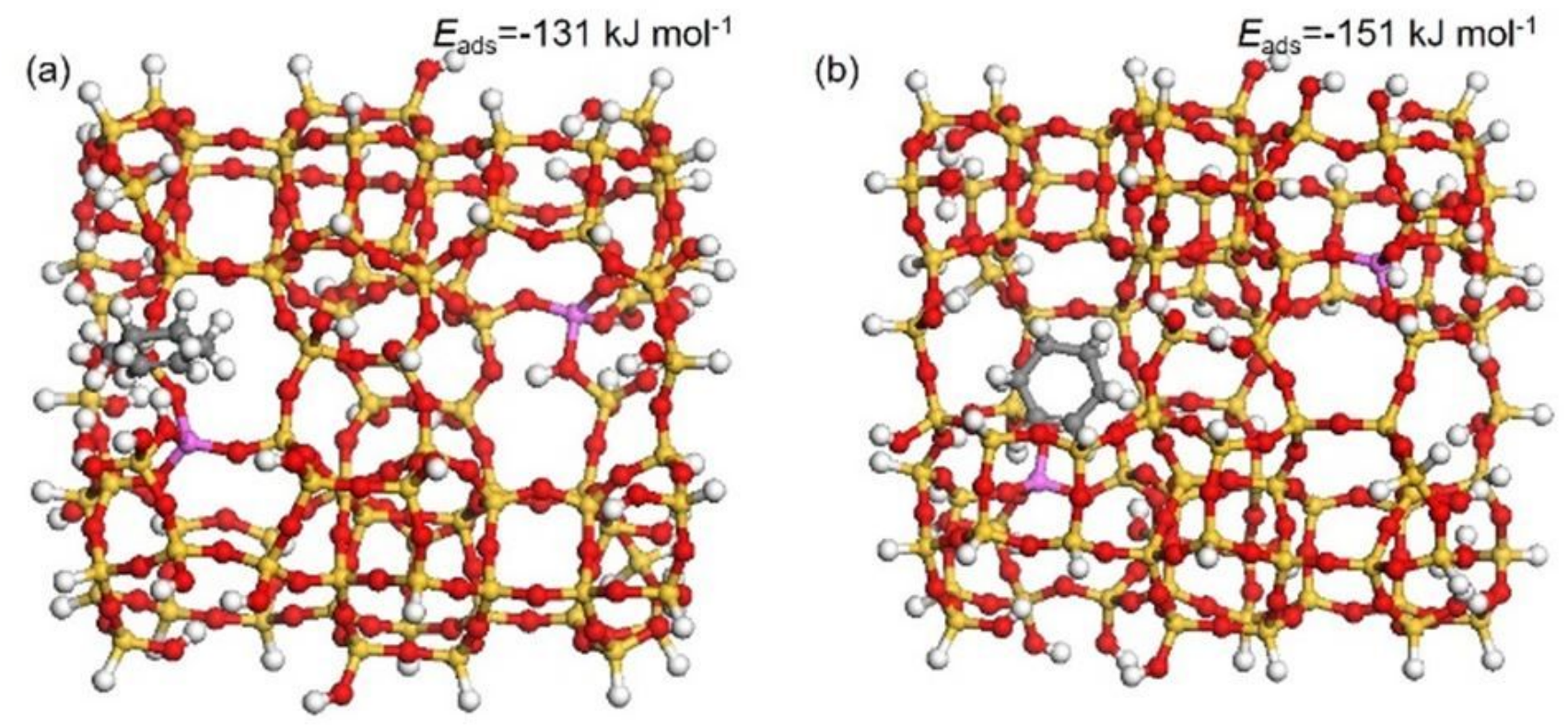

Figure 8

Optimized structure of adsorbed cyclohexene (a) on the external surface, (b) within the internal pore of zeolite-based catalyst. The corresponding adsorption energies Eads are also given.

\section{Supplementary Files}


This is a list of supplementary files associated with this preprint. Click to download.

- SupportingInformationCommChem.doc

- SupportingInformationCommChem.doc

- Scheme1.JPG

- Scheme1.JPG 